The organization of the trial was described in detail by Professor J. C. Goligher and his colleagues in 1964. ${ }^{3}$ The trial was restricted to patients undergoing elective surgical treatment for duodenal ulcer. An "escape clause" was introduced, so that if in a particular case the surgeon decided preoperatively that a particular operation was indicated such a patient could be taken out of the trial. Thus the surgeon might consider that a patient who had had pulmonary tuberculosis should not be subjected to gastrectomy. At operation, once again, the surgeon could decide to take the patient out of the trial if it seemed that a particular operation was necessary. The usual case was that of a deeply penetrating posterior ulcer, when gastrectomy might be hazardous and vagotomy with gastrojejunostomy more appropriate. But once the surgeon had decided at operation that the patient was suitable for entry into the trial then a sealed envelope of instruction was opened to discover which of the three operations was to be performed. The envelopes had been prearranged to give a random distribution of the different operations under trial. Subsequent follow-up was carried out by a small panel who generally did not know which operation has been performed until after they had recorded their findings and verdict. This assessment of results has been conducted yearly.

The trial now reported on again (p. 781) covered the period of three years from April 1959, during which time 634 patients were operated on-507 men and 127 women. Of the 507 male patients no fewer than 132 were rejected from the trial. Of the 375 males accepted approximately equal numbers were allocated to the three operations. Most of those rejected were treated by vagotomy and gastroenterostomy. The surgeons concerned in the trial are to be congratulated in that the operative mortality of this large series of 634 patients was zero.

After a thorough analysis of the follow-up results the authors are unable to make a dogmatic statement about the superiority of any one operation over the others, since the overall clinical results failed to show any statistically significant difference. But there is a bias in favour of vagotomy with antrectomy and of subtotal gastrectomy over vagotomy with gastroenterostomy. The two former operations seem to offer better protection against stomal ulceration and rather better functional results than vagotomy and gastroenterostomy.

These findings must be considered in relation to others. The experience at other centres with regard to operative mortality is not so happy as in the present study. The average mortality in partial gastrectomy is in the region of $2-5 \%$, yet most studies of vagotomy and drainage give a lower mortality in the range of $0.5-1 \%$. Obviously this is an important consideration. Furthermore, the metabolic effects of vagotomy combined with simple drainage are less profound than those following gastrectomy, ${ }^{4}$ and this too must add weight to the arguments for the simpler operation.

Professor Goligher and his colleagues then go on to report at page 787 a more recent study in a series of 175 men with duodenal ulcer treated by total vagotomy and pyloroplasty since January 1963. There were two deaths in the immediate postoperative period due to acute cardiac failure. Two years after operation 158 patients have been interviewed and

\footnotetext{
1 Brit. med. F., 1968, 1, 461.

Cox, A. G., Brit. med. ₹., 1968, 1, 288.

S Goligher, J. C., Pulvertaft, C. N., and Watkinson, G., Brit. med. F., 1964, 1, 455.

- Wastell, C., Postgrad. med. ₹., 1967, 43, 481.
}

examined. Though the follow-up period is comparatively short, there has not been any lower incidence of symptoms of alimentary dysfunction after pyloroplasty than was found in the previous study after vagotomy and gastroenterostomy. Against this is a higher tendency for recurrent ulceration after pyloroplasty than after gastroenterostomy.

These findings, though still somewhat tentative, cast doubt on sweeping statements made by advocates of their own particular favourite procedure in the surgery of duodenal ulceration. Perhaps their greatest importance is in pointing a way to the future. The more carefully designed prospective studies of this type which are carried out the sooner shall we be able to obtain the answers to the many vexing questions which face the surgeon today in his choice of operation for a particular patient suffering from this common affliction.

\section{Controversy in Wilson's Disease}

Wilson's disease has always excited interest and controversy, ${ }^{1}$ and never was this more true than at present, as readers of the New England fournal of Medicine will have realized. The current controversy started after a paper of I. Sternlieb and I. H. Scheinberg, ${ }^{2}$ which described the treatment of symptom-free relatives of patients with the disease with prophylactic penicillamine. Though these relatives had none of the clinical signs of Wilson's disease, they were thought to be homozygous for the abnormal gene because of the finding of a low caeruloplasmin level in the plasma and a high copper concentration in the liver. Of the 34 patients in whom adequate liver-biopsy material was available, five showed no abnormality on light microscopy, eleven had definite cirrhosis, and the remainder showed fatty change with or without portal tract fibrosis. During the period of observation amounting to 142 patient-years for the 42 relatives treated, none has developed signs of the disease. From a retrospective analysis of a group of 121 patients with Wilson's disease the authors estimated that without treatment at least eight of these relatives would have been expected to develop the disorder. Five relatives have now reached or passed the age at which their older siblings became overtly ill with the disease.

The setting up of a properly randomized therapeutic trial would have required withholding treatment from half of these asymptomatic homozygotes. Steinlieb and Scheinberg argued that this was ethically unjustifiable in view of the known beneficial effects of penicillamine therapy in Wilson's disease and the results of their retrospective analysis. Other workers, including J. M. Walshe ${ }^{3}$ and A. J. Levi and his colleagues ${ }^{4}$ in Britain, who have a further 11 asymptomatic relatives on prophylactic penicillamine therapy, would agree with this view. But $\mathrm{H}$. Muench ${ }^{5}$ and some of the statisticians who initially reviewed the paper have their doubts. ${ }^{6}$ Is the statistical evidence sufficiently strong to merit the lifelong commitment of asymptomatic subjects to a drug which produces an

Brit. med. F., 1967, 4, 435

2 Sternlieb, I., and Scheinberg, I. H., New Engl. f. Med., 1968, 278, 352.

3 Walshe, J. M., New Engl. F. Med., 1968, 278, 795.

- Levi, A. J., Sherlock, S., Scheuer, P. J., and Cumings, J. N., Lancet, 1967, 2, 575 .

s Muench, H. New Engl. 7. Med., 1968, 278, 796.

6 New Engl. fे. Med., 1968, 278, 392

Osborn, S. B., and Walshe, J. M., Clin. Sci., 1964, 27, 319.

* Levi, A. J., and Williams, H. S., Clin. Sci., 1968, 34, 379. 
appreciable incidence of toxic effects? Probably only time will give a definite answer.

The distinction of a pre-symptomatic homozygote from the heterozygote of Wilson's disease-who, though frequently showing some abnormality in copper metabolism, will not develop the disease-requires the fullest investigation, including liver biopsy. About $10 \%$ of heterozygotes have a reduced level of caeruloplasmin in the serum, and concentration of copper in the liver may be moderately increased, though levels above $250 \mu \mathrm{g} . / \mathrm{g}$. dry weight are found only in the homozygous state. ${ }^{24}$ The histochemical staining of liver biopsies for copper is unreliable, as are several other screening tests such as the presence of a low serum uric acid level or amineaciduria detectable by chromatography of the urine. The relatively simple radioisotope test developed by S. B. Osborn and J. M. Walshe, ${ }^{7}$ in which the counting rate over the liver is compared with that over the thigh after the intravenous injection of copper-64 chloride may not separate the presymptomatic homozygote from the heterozygote, and, indeed, the specificity of this test has been questioned recently after low values have been found in other varieties of cirrhosis. ${ }^{8}$ Nevertheless, there can be no question that the diagnosis of a case of Wilson's disease must lead to most thorough and careful examination of the patient's brothers and sisters.

\section{Helicopters and Medical Emergencies}

Air ambulance units in Vietnam carried 94,000 casualties $^{1}$ by helicopter in 1967 . All military casualties in the war are now within 35 minutes' flying time of resuscitation units on the ground. Again, the value of helicopters in the junglecovered mountains of the Malay Peninsula is evident from the article by Dr. J. M. Bolton at page 818 of the B.M.f. this wcek. He shows how medical services can be brought right into the heart of singularly inaccessible territory.

Conditions in Great Britain pose very different problems, though even here 100 or so sick and injured persons are carried by helicopter each year. Helicopters are provided by the Services on request by medical officers of health, and their tasks fall into two groups. The first is the removal of sick and injured persons from ships at sea or from inaccessible areas such as mountains or remote islands. The second is the conveyance by air of patients for whom the delay or the disturbance of a long journey by road is considered undesirable. Most of the medical helicopter flights in Britain are of this second type and are arranged at leisure rather than as emergencies. Nevertheless, the helicopters can become airborne within a few minutes of being requested. It is remarkable, and also reassuring, that even in Britain weather very rarely interferes with operations of this sort.

From time to time there have been suggestions that helicopters should play a larger part than they do in the conveyance of injured persons, but such suggestions need to be considered realistically. Unlike the casualties of war, the casualties of peace are not predictable in terms of time, place, and number, and at the present time there can be little alternative to a rather sparse network of machines that are themselves readily available but not necessarily close at hand.

\footnotetext{
${ }^{1}$ Neel, S., 7. Amer. med. Ass., 1968, 204, 309.
}

Furthermore, in peacetime the purse strings are tightly drawn and the Services charge $£ 50$ or $£ 124$ an hour according to the machine that is used. Before calling for a helicopter, doctors should weigh carefully the advantages and disadvantages of the different methods of conveyance and consider particularly the possibility that the slower vehicle may arrive first, since it usually covers a much shorter distance. The larger accident centres should be designed to enable helicopters to land, but we should not expect to see many more of them at work carrying patients.

\section{L.S.D. and Chromosomes}

The question whether lysergic acid diethylamide (L.S.D.) damages the chromosomes is still undecided, but because the drug is used in psychiatric medicine and as a hallucinogen for "kicks" it needs thorough study. ${ }^{1}$ In general, work on L.S.D. as a chromosome-breaking agent has been of three types-namely, direct in-vivo studies of people who have taken it therapeutically or illicitly, in-vitro studies of lymphocyte cultures treated with L.S.D., and finally in-vivo and in-vitro studies on experimental animals.

The in-vivo studies on patients have generally proved to be inconclusive and sometimes contradictory. M. M. Cohen and his co-workers ${ }^{3}$ report chromatid aberrations in a series of 18 patients who had taken different doses of L.S.D. for various times and who had also taken other drugs either previously or at the same time as L.S.D. This group of workers also examined the chromosomes of four children of three mothers who had taken L.S.D. during pregnancy, and found a raised frequency of breakage in two children whose mothers had taken a high dosage $(300-600 \mu \mathrm{g}$. per dose) of the drug during the first three to four months of pregnancy. Low doses later in pregnancy had an insignificant effect. Similar results were obtained by S. Irwin and J. Egozcue ${ }^{4}$ in six out of eight patients taking the drug, and these workers also observed a " $\mathrm{Ph}^{1}$-like chromosome" in two users of the drug (the "Philadelphia" chromosome is found in some cases of leukaemia). H. Zellweger and colleagues ${ }^{5}$ report chromosome breakage in the parents of a congenitally malformed child who had taken the drug during pregnancy and postulate a causal association between the congenital malformation. and the drug, but this needs confirmation. This week Dr. J. Nielsen and colleagues report in the B.M.F. at page 801 that they found a statistically significant increase of damaged

Brit. med. F., 1967, 4, 124

${ }^{2}$ Cohen, M. M., Marinello, M. J., and Back, N., Science, 1967, 155, 1417 .

${ }^{3}$ Cohen, M. M., Hirschhorn, K., and Frosch, W. A., New Engl. \}. Med., 1967, 277, 1043.

4 Irivin, S., and Egozcue, J., Science, 1967, 157, 313.

5 Zellweger, H., McDonald, J. S., and Abbo, G., Lancet, 1967, 2, 1066.

Sato, H., and Pergament, E., Lancet, 1968, 1, 639.

Loughman, W. D., Sargent, T. W., and Israelstam, D. M., Science, 1967, 158, 508.

" Cohen, M. M., Hirschhorn, K., and Frosch, W. A., New Engl. \}. Med. 1968, 278, 223.

${ }^{9}$ Jarvik, L. F., and Kato, T., Lancet, 1968, 1, 250.

10 Jagiello, G., and Polani, P. E., unpublished.

11 Jagiello, G., Science, 1967, 157, 453.

12 Jagiello, G., Mutation Res., in press.

13 Al.xander, G. J., Miles, B. E., Gold, G. M., and Alexander, R. B., Science, $1967,157,459$

14 Auerbach, E. R., and Rugowski, J. A., Science, 1967, 157, 1325.

15 Geber, W F., Science, 1967, 158, 265.

16 Fabro, S., and Sieber, S. M., Lancet, 1968, 1, 639. 